\title{
Advances in Understanding of Neurophysiological Function of the Fetus
}

\author{
${ }^{1}$ Aida Saligahić Kadić, ${ }^{2}$ Filip Glavač, ${ }^{3}$ Oliver Vasilj
}

\begin{abstract}
The fascinating journey of the human life begins with two cells merging and continuing to grow into a perfectly designed apparatus comprised of multiple systems working together. Even before one draws his first breath, our nervous system plays the key role of creating a synergy in every single action and process. It all begins during fetal development, which can nowadays be observed and studied through modern imaging technologies, such as ultrasound. This gives the reader an insight on how every part of the nervous system develops and correlates with the developing body using a minimally invasive approach. This article gives an assessment of the knowledge we have regarding fetal neurophysiology and what has been learned about fetal motor and sensory development so far, as well as memory and learning, behavior and emotions and fetal cognitive functions reviewed for selected sections. Furthermore, the article provides a review of how different external factors can harm the fetus and how fetal stress presents a potential threat in fetal neurodevelopment with lasting consequences on brain structure and function. The complexity and maturation processes build up during pregnancy and continue postnatally, allowing further accommodation and development to show the astonishing capacity of brain to learn and adapt.
\end{abstract}

Keywords: Emotions, Fetal movements and action, Fetal sensory perception, Fetal stress, Four-dimensional ultrasound, Memory and learning.

How to cite this article: Salihagić Kadić A, Glavač F, Vasilj O. Advances in Understanding of Neurophysiological Function of the Fetus. Donald School J Ultrasound Obstet Gynecol 2018;12(1):23-31.

Source of support: Nil

Conflict of interest: None

\section{INTRODUCTION}

Researching the human fetus has progressed in the past decade by dint of four-dimensional (4D) ultrasound giving the researchers an insight into fetal intrauterine activities. Special attentiveness is given to the

\footnotetext{
${ }^{1}$ Professor, ${ }^{2}$ Medical Student, ${ }^{3}$ Assistant

1,2Department of Physiology, School of Medicine, University of Zagreb, Zagreb, Croatia

${ }^{3}$ Department of Obstetrics and Gynecology, Clinical Hospital "Sveti Duh", School of Medicine, University of Zagreb, Zagreb Croatia

Corresponding Author: Aida Salihagić Kadić, Professor Department of Physiology, School of Medicine, University of Zagreb, Zagreb, Croatia, Phone: +38514566763 , e-mail: aida. salihagic@mef.hr
}

development of the nervous system due to its extensive progress and development during embryonic and fetal life. The maturation of the fetal central nervous system (CNS) is reflected in areas of motor and sensory development, fetal memory, and learning, emotions, and behavior, and their clinical significance as well as the role of stress in neurodevelopment, and its physiological response mechanisms. This article provides a revision of points of interest in fetal neurophysiology and neurodevelopment with a clinical review of the potential threats during intrauterine development.

\section{FETAL MOVEMENTS AND ACTION}

Many studies provide evidence that tracking fetal motility correlates with how the fetal CNS and other systems develop and maturate even before the mother can feel the fetus moving. ${ }^{1,2}$

Starting with the first trimester where most types of movement patterns become apparent, ${ }^{3}$ the early embryonic development marks the beginning of early synaptogenesis in both the spinal cord ${ }^{4}$ from weeks 6 to 7 and the brainstem $^{5,6}$ from week 7 , continuing with the basic structures of the diencephalon and cerebral hemispheres by the end of the 8th week. The first complex, well-organized movement patterns also known as general movements which include head, trunk, and limb movements appear at the end of the 8th gestational week. ${ }^{7}$ As the brainstem maturates and the primary medulla oblongata and pons form along with cranial nerves V-XII, actions of isolated limb movements, breathing-like and facial movements can be seen. ${ }^{2,5}$ As of week 10 , lateralization and signs of right- or left-handedness are evinced subsequent to motor activity stimulating the fetal brain. ${ }^{8,9}$ Later, in the 13th week of gestation, a "goal orientation" of hand movements is visible and a target point for each hand movement can be deduced. ${ }^{10}$

The second trimester is salient by gradual organization of fetal movement patterns (Figs 1 and 2). The periods of fetal quiescence begin to increase, and the rest-activity cycles become recognizable. Behavioral patterns expand and become more complex through the 15 th week of gestation due to brain stem maturation. First eye movements are noticed between 16th and 18th week of gestation as sporadic movements with limited frequency. ${ }^{2}$ Earliest electrocortical activity is preceded by the development of the subplate zone which is accompanied with growth of 


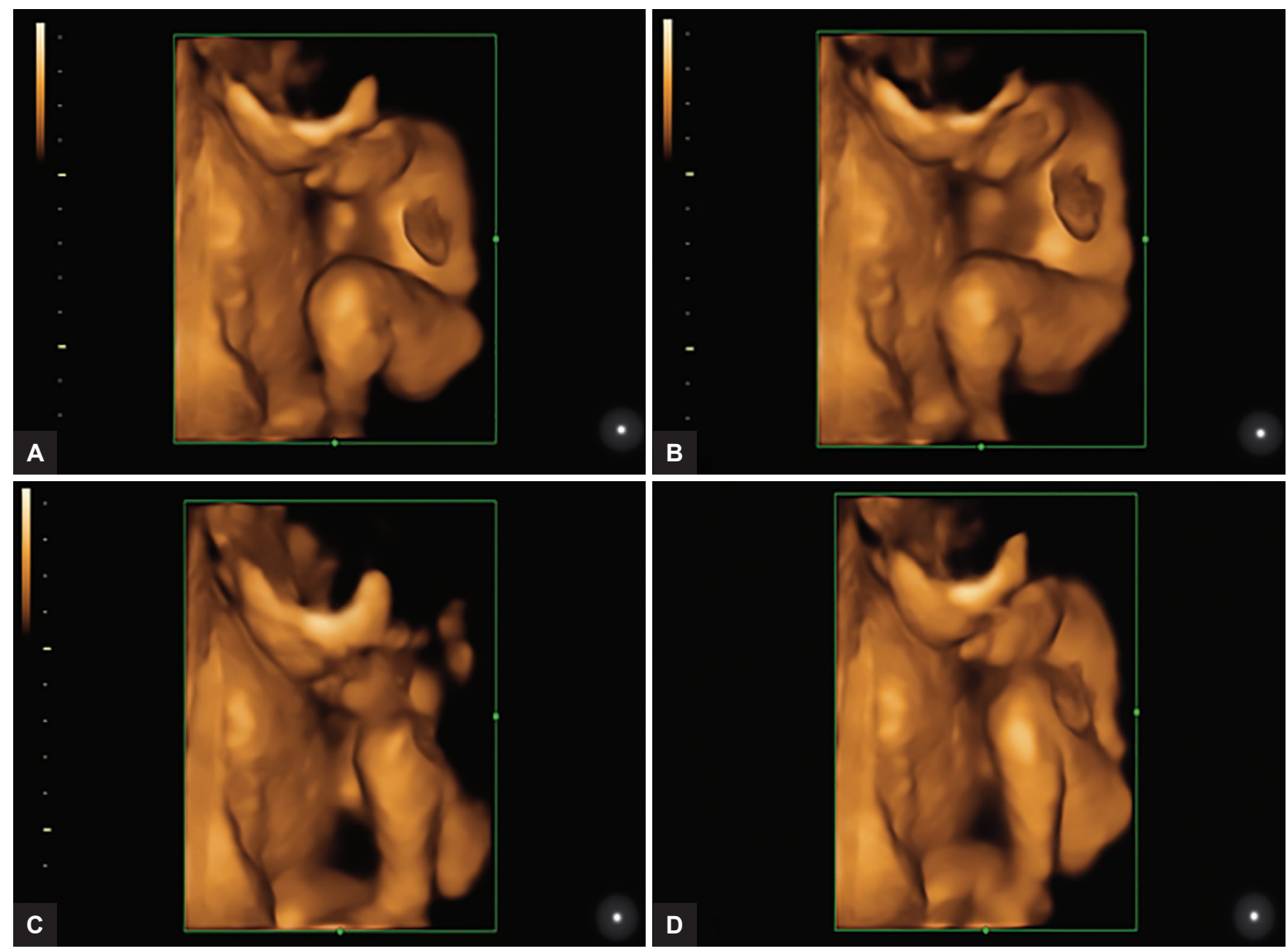

Figs 1A to D: Sequence of 4D ultrasound images of the fetus moving its leg in the second trimester

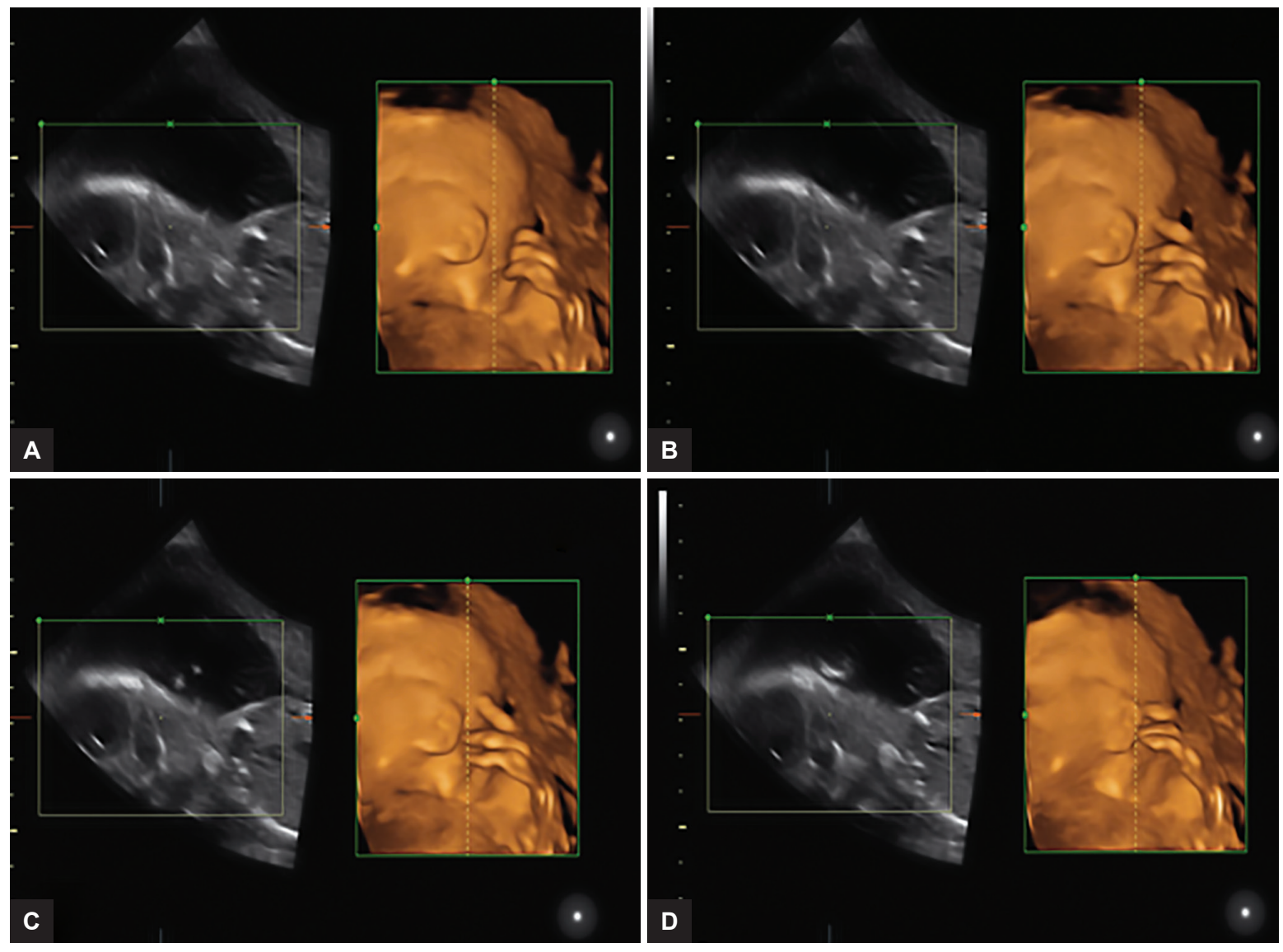

Figs 2A to D: Sequence of 4D ultrasound images of the fetus moving its fingers in the second trimester 
cortical synapses. ${ }^{11,12}$ The most frequent facial movement patterns in the second trimester were isolated eye blinking pattern, grimacing, sucking, and swallowing. ${ }^{7}$ The lower motor system clinically matures ${ }^{13}$ and the spinothalamic tract is established; ${ }^{14,15}$ yet, the immature cerebral circuits have small involvement in motor actions. ${ }^{11,12}$ The fetus begins to establish a circadian rhythm with increased periods of fetal quiescence, making rest-activity cycles more recognizable. ${ }^{2}$

The third trimester is marked with general development of all major systems and functions of the fetus. First evoked potentials are registered between 26 and 28 weeks, indicating functional connections between the periphery and the cortex. ${ }^{16}$ The upper motor cortex develops later than the lower and becomes clinically significant at 34th gestational week. ${ }^{13}$ The cortex starts to differentiate ${ }^{12}$ into areas and a six-layered lamination is seen from 32nd week and beyond. ${ }^{17}$ Association cortices, however, are less clearly delineated at this period. ${ }^{18}$ With everything mentioned hitherto, it should be noted that the brainstem subunits remain main regulators of all fetal behavior until delivery. ${ }^{5}$ Nevertheless, developmental trends in fetal motor patterns may indicate the establishment of control of more cranial brain structures. ${ }^{2}$ The brainstem, midbrain, and pons mature further and increase the complexity of both general and eye movements with a distinguishable sleep-wakefulness patterns beyond week $30 .{ }^{2,19,20}$ A stagnancy or downfall in the frequency of facial movements which peaks at the end of second trimester has been noticed. Detected intentional and planned movements point out to an advanced level of fetal motor planning. ${ }^{21}$ Based on the assessment of fetal spontaneous motor activity by $4 \mathrm{D}$ ultrasound, a prenatal neurologic scoring test named KANET (the Kurjak Antenatal Neurodevelopmental Test) was introduced. ${ }^{22}$ This test has been used to assess over 2,000 fetuses and the results have shown that KANET has an ability to recognize normal, borderline, and abnormal behavior in fetuses from normal and pathological pregnancies. ${ }^{23-27}$ It should be noted that no movements found in fetal life are absent in neonatal life with a subtle prenatal-neonatal continuity. $^{28,29}$

Specialized movement patterns, crucial for the survival of newborns, such as swallowing and respiratory movements, also develop and mature during gestation and are important during intrauterine life. ${ }^{2}$ Furthermore, recent data indicate that fetal movements serve not only to express different orientations, but also emotional states and manifestations of intentions. ${ }^{30}$ External factors, such as smoking and mother's emotional stress influence the number of fetal movements and development heavily. ${ }^{31,32}$ Similar outcomes have been shown in cases of maternal diabetes mellitus, fetal anencephaly, and intrauterine growth restriction (IUGR), ${ }^{33}$ resulting in accelerated development of most functions, apart from all brain functions. ${ }^{34}$ It has been recently shown that primary sensory motor and affective integration errors and poorly regulated motor intentions underlie autistic spectrum disorders. ${ }^{35}$

By modifying motor experiences prenatally and postnatally the prefrontal cortex, which functions to plan and direct motor, cognitive, affective, and social behavior, can be changed dramatically by events beginning prenatally and throughout the life span. ${ }^{36}$ Synchronized communication across the neural systems responsible for higher-order cognitive functioning ${ }^{37}$ is possible with white matter myelination starting late in embryonic development and continuing throughout the postnatal life. Formed around the 18th week of gestation, the corpus callosum represents an integrative part of white matter for sensory, motor, cognitive, and emotional functions from both hemispheres. Abnormal volumes are associated with learning and behavioral difficulties, speech and language delays, cognitive, and motor impairments, including cerebral palsy. ${ }^{37}$

\section{FETAL SENSORY PERCEPTION}

Some of the first sensations to develop during intrauterine life are touch and pain with perioral region, hands and lower limbs becoming touch sensitive early in fetal development. ${ }^{2}$ By 14 weeks of gestation, most of the body, excluding the back and top of the head, is responsive to touch $^{34}$ with motor reflexes driven by the spinal cord and its afferent-efferent circuits. Following the instalment of thalamocortical pathways around 23rd week of gestation, the primary somatosensory cortex, along with other cortical areas differentiates, ${ }^{14,15}$ continuing in the postnatal period, allowing tactile sensations to be processed. Along with cortico-cortical connections, it is fundamental for cortical processing of sensory information and mental processes. Body consciousness arises around 25th week of gestation linking it with the emergence of a minimum level of consciousness. ${ }^{38}$

With the development of first nociceptors during 7 th week of gestation, first reactions to painful stimuli can be detected. Painful stimuli of appropriately innervated areas trigger a wide spectrum of physiological reactions activating the hypothalamus-hypophysis axis or the autonomic without reaching the cortex which can be suppressed by analgesics. In order for a fetus to sense and process pain, an according pathway is established with necessary connections by the 26th week of gestation. Recordings of somatosensory evoked potentials (SEP) during 29th week of gestation provide evidence of a fully functional and operating pathway. ${ }^{2}$ Along with 
physiological changes of heart rate and blood oxygen saturation ${ }^{39,40}$ fetal facial expressions similar to those of children sustaining pain have been noticed by $4 \mathrm{D}$ sonography becoming more complete as gestational age increases and may be considered an adaptive process which is useful to the fetus postnatally. ${ }^{41}$ Prenatal and/ or neonatal exposure to pain results in prolonged stress response and may alter pain thresholds as well as abnormal pain-related behavior later in life. ${ }^{42}$ Despite the great interest of scientists in fetal conscious experience and memory of pain, unconscious reactions, such as the secretion of stress hormones and their far-reaching adverse effects are probably more dangerous for the development of the fetus than terrifying memories. ${ }^{43}$

Flavors from mother's diet during pregnancy are transmitted to the fetus via amniotic fluid and can be sensed since 7th week of gestation with the development of taste buds. This provides evidence for the acquired food taste, previous to first solid food intake. ${ }^{43-45}$ Sense of smell is processed from 20th week of gestation onward through the orbitofrontal cortex. Behavioral responses to pleasant and unpleasant olfactory sensations can be recorded in preterm infants from about the 29th week. The fetus is also able to express pleasure or disapproval of tastes and smells. ${ }^{46}$

It is believed that thirst, satiety, and appetite mechanisms are developed prenatally with studies providing evidence on modulation of fetal swallowing and argininevasopressin secretion in changed osmotic environment. ${ }^{47-49}$ Neuropeptide $Y$ and leptin represent the main feeding regulatory factors, with both NPY and leptin being orexigenic factors in fetuses, increasing fetal swallowing. Although leptin serves as an anorexigenic factor in adults, it is believed by some that the number of leptininhibitory responses plays a role in satiety in fetuses. ${ }^{50}$

As with any other sense, it is essential for the fetus to be exposed to visual stimuli for the appropriate development of vision. This thesis has been experimentally confirmed with the fetus reacting to a flash stimulus over the maternal abdomen with the visual evoked brain activity, recorded by magnetoencephalography, from the 28th gestational week onward. ${ }^{51}$ Visual connections between the subunits of the visual path that are established by midgestation continue to develop afterward. ${ }^{52}$ In the primary visual cortex, synaptogenesis persists between 24 weeks of gestation and 8 months after birth. Continuing even after birth, the first surface-positive evoked potentials that are recorded between the 36th and 40th week distinguish the maturation of visual cortex. Furthermore, fetal eye motility takes part in the functional maturation of the eye and retinal (neuronal) cell differentiation., 2,43

The development of the cochlear function spans from between 22 and 25 weeks of gestation to the first
6 months after delivery, showing that fetuses respond to auditory stimuli even before their mothers can sense their reactions. Prolonged pontine maturation correlates with delayed selective response to sounds. Reflexive body movements, head-turning, and heart-rate acceleration are characteristic responses of the fetus to external noise from the 36th week of gestation to delivery with an ability to discriminate different sounds. The selective preference for mother's voice and other familiar voices is attributed to the tonotopic organization of the cochlear nuclear and the maturation of the brainstem during the last weeks of pregnancy. ${ }^{5}$ It provides strong evidence to brainstem's learning-related activity. The synaptic plasticity of the brainstem nuclei and their pathways makes them susceptible to the external auditory experience and capable of "synaptic learning". That is to say, the repetitive auditory stimulation, or lack thereof, forges these networks and pathways, which in turn, selectively respond to the stimuli that shaped them.

\section{FETAL MEMORY AND LEARNING}

Owing to methods, such as habituation, classical conditioning and exposure learning made our knowledge on fetal memory and learning more extensive.

Fetuses demonstrated learning by habituation, the decrement in response following repeated presentation of the same stimulus from 22 weeks of gestation onward ${ }^{53}$ with the prefrontal and hippocampal regions being key elements in the orienting response. ${ }^{54}$ It has been proved that younger fetuses need more exposure to vibroacoustic stimuli than older ones in order to register certain developmental trends. Fetal habituation can be affected in a negative manner, as a consequence of maternal stress and depression, resulting in developmental delays that may be linked to impaired function of the fetal cerebral cortex. $^{55}$

Classical conditioning is the method which involves the pairing of two stimuli: A conditioned stimulus (which elicits no response when presented alone) and an unconditioned stimulus (which elicits a fetal response when presented alone). Following repeated paired exposure to these two stimuli, the conditioned stimulus also elicits a response termed a "conditioned response". It has been demonstrated with fetuses from 32 to 39 weeks of gestation, although it could be demonstrated with anencephalic fetuses as well. Studies in chimpanzee models, using classical conditioning, have shown that fetuses can learn and retain obtained information for at least 2 months after delivery. ${ }^{56}$

Reexposing the fetus to a stimulus after a number of exposures and then comparing the response either to the response to the "unfamiliar" stimulus or to the response of an unexposed fetuses to the same stimulus, also known 
as exposure learning, is the third method used in investigating fetal memory and learning. Results were shown with fetuses at 37 weeks of gestation, whereas various reactions with fetuses at 30 weeks of gestation to familiar and unfamiliar were left out. ${ }^{57}$ This method gives insight into fetal preference of the voice of their mother over an unacquainted one as well as preferring the mother's voice in utero over the mother's voice after birth. These findings confirmed that fetuses are able to hear and learn their mother's voice before birth. ${ }^{58}$ Recent data reported on selective fetal cortical processing for the mother's vs an unfamiliar voice at 34 weeks of gestation. ${ }^{59}$ Other studies report that the fetus is able to learn and remember familiar auditory stimuli, and retain this information over the birth period. ${ }^{60}$ It has been shown that rudimentary capacity for retention of information may be expressed as early as 30 weeks of gestation and prenatally acquired auditory memory can last even 6 weeks. ${ }^{61}$

Other methods indicate that the fetus can learn tastes and acquire taste preference ${ }^{45}$ and learn through smell. By discriminating different speech sounds in the womb $b^{57,58}$ the fetus may begin the process of acquiring language prenatally. Lastly, prenatal learning and memory could play an important role in the development of maternal recognition, attachment, feeding behavior, and social recognition. ${ }^{2}$ The long-term auditory memory might play a role in the developmental psychobiology of attention and perception, including early speech perception. ${ }^{61}$

\section{FETAL EMOTIONS}

Emotions emerge in fetal life. ${ }^{62}$ The easiest way to interpret emotions is by examining facial expressions. The existence of a full range of facial expressions, including grimacing, smiling, crying, similar to emotional expressions in adults (Fig. 3), has been revealed by 4D sonography in the 2nd

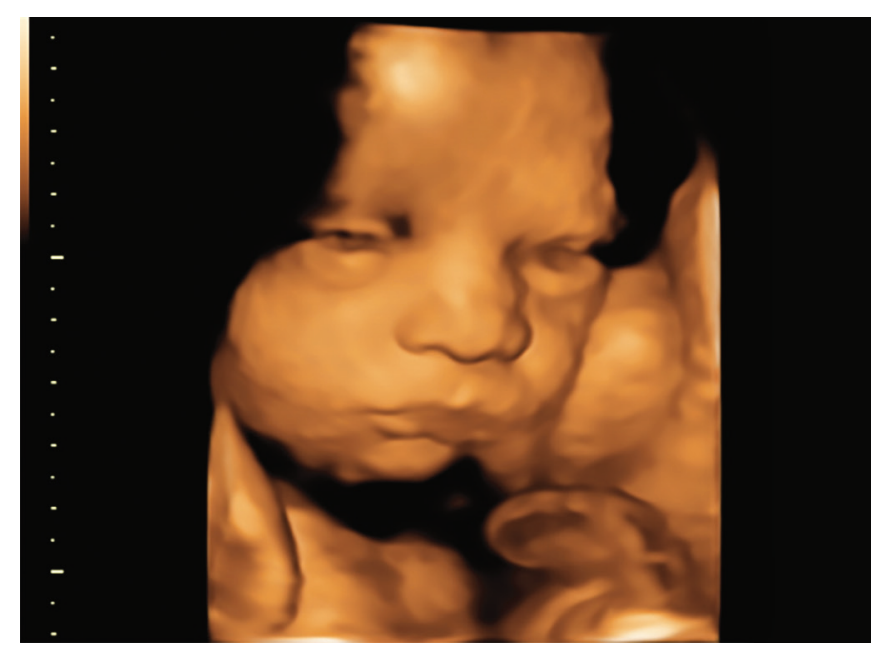

Fig. 3: The 4D ultrasound presenting a still face that resembles a facial expression in a calm and reflective state of the fetus in the third trimester and 3rd trimesters of pregnancy.,63 The complexity of facial expressions increases with appearance of "cry-face gestalt" or "laughter-face gestalt" that progresses during maturation in the third trimester. ${ }^{64}$ Moreover, according to the observations obtained by 4D ultrasound, the facial expressions and emotion-like behaviors may represent some kind of fetal emotion and awareness. ${ }^{65}$

The limbic forebrain is responsible for the expression and experience of emotions ${ }^{66}$ with the amygdala mediating motional memory, attention, arousal, and the experience of love, fear, pleasure, and joy. Its development begins at early embryonic life ${ }^{67}$ and reaches an advanced stage of maturity during the first postnatal year, ${ }^{66}$ allowing the fetus to evaluate faces in social processing and discern the emotional significance of different facial expressions.

\section{FETAL STRESS}

Stress plays a key role in its protection of the organism. Many adaptive changes induced by fetal stress increase the fetal survival rate by creating a short-term protection. However, these changes can leave profound alterations in the structure and functions of the organism, especially affecting neurodevelopment. ${ }^{6}$ Triggers that alter the intrauterine environment, such as maternal undernutrition or placental insufficiency, ${ }^{68}$ as well as painful stimuli, ${ }^{69}$ severe maternal emotional stress or stressful life events, ${ }^{70-72}$ can cause fetal stress. It has been shown that raised endogenous glucocorticoids are known mediators of growth restriction and as such are found in IUGR pregnancies ${ }^{73}$ with increased fetal cortisol levels. The results of the case study obtained by KANET have indicated that the quality and quantity of movements in growth-restricted fetuses were significantly altered with a deficient repertoire of fetal movements and abnormal general movements. The fetus with severe hypoxia had neurological thumb (Fig. 4) and his face was like a mask. ${ }^{74}$

The neuroendocrine stress axis includes the production and secretion of the corticotropin-releasing hormone (CRH), adrenocorticotropic hormone (ACTH), and cortisol. Stress stimulates the hypothalamus to release $\mathrm{CRH}$ into the hypophyseal portal system causing a release of ACTH into the peripheral blood circulation. The ACTH stimulates secretion of glucocorticoid hormone, cortisol, from the adrenal glands. This axis operates in the fetus from mid-gestation. ${ }^{43}$ Fetal $\mathrm{CRH}$ influences the timing of birth, portraying the fetuses' active role in the initiation of parturition. Additionally, studies show that fetal ACTH influences negatively on motor functions, impairing motor coordination and muscle tonicity, as well as reducing the attention span and increasing irritability. ${ }^{2,43}$ Moreover, recent investigations report that overexposure 

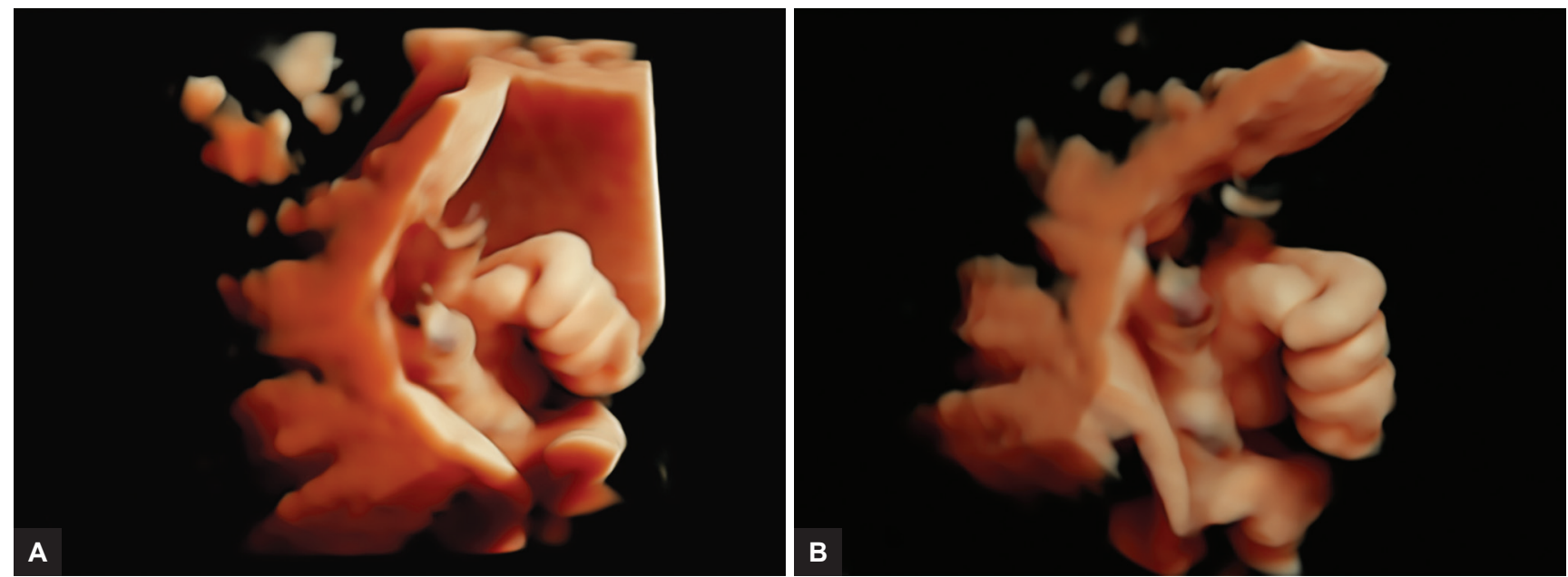

Figs $4 A$ and B: Sequence of HD live mode images of fetal neurological thumb in a clenched fist

to glucocorticoids can result in premature cessation of fetal cell proliferation, leading to fetal growth restriction ${ }^{75}$ and accelerated maturation of the brain with both structural and behavioral changes, such as hyper-alertness and impaired fetal responsiveness to novel stimuli. ${ }^{76}$ Structural changes of the hippocampus ${ }^{77-80}$ are associated with memory impairment and learning disabilities later in life. Increased maternal stress has been linked to long-term neurodevelopment effects on the infant ${ }^{81-84}$ including a wide spectrum of disorders and disturbances: Attention deficit hyperactivity disorder, ${ }^{85}$ sleep disturbances, unsociable and inconsiderate behavior, as well as psychiatric disorders, including schizophrenic episodes, depressive and neurotic symptoms, drug abuse, mood, and anxiety. ${ }^{86}$ Fortunately, many investigations have shown that increased maternal care and environmental enrichment can compensate for prenatal stress-induced effects. ${ }^{87-89}$ Recent study has also indicated that infant cognitive development can be moderated by infant-mother attachment. $^{90}$

\section{CONCLUSION}

The use of 4D ultrasound allows us to monitor functional and structural brain development through fetal motor parameters and behavior. Additionally, it proves that the fetus needs a stimulating matrix of motion as well as tactile, chemical, and auditory sensory information and other stimuli for the brain and other organs and organ systems to develop properly.

The extraordinary property of synaptic plasticity is shown in the primary auditory cortex before the brain has reached full-term maturation regarding experiencedependent plasticity. This demonstrates that the fetus can detect, respond to, and remember for a relatively long time stimuli experienced during the prenatal period. By developing functional thalamocortical and corticocortical connections, the link between the periphery and cortex is established, allowing the fetus to register and process noxious stimuli.

From developing preference for mother's voice, through retaining memory postnatally, and acquiring taste preferences, the fetus shows profound and complex ability to learn and memorize certain stimuli through various methods. A new wave of investigations has also indicated that emotion-like behaviors and roots of emotions appear during fetal life. The later the stages of development and maturation come, the more complex processes take place, culminating with the development of cognitive functions at the end of pregnancy subsequent to development of primary cortical areas. The issue of fetal cognitive functions has been not only an object of interest for scientists, but also an important issue in clinical practice. With advancement in linking facial expressions to certain developmental stages as well as certain pathological states combined with the promising KANET score, it has become easier to distinguish the boundary between the pathological and the physiological conditions. Advances in medical diagnostics and technology allow prenatal and postnatal medical interventions.

To sum up, in order for the fetus to grow properly, he needs a stress-free environment abundant with various stimuli for normal development of the brain and other organs and organ systems.

\section{REFERENCES}

1. Nijhuis JG. Fetal behavior. Neurbiol Aging 2003 May-Jun;24 Suppl 1:41-46.

2. Salihagic Kadic A, Predojevic M, Kurjak A. Advances in fetal neurophysiology. In: Pooh RK, Kurjak A, editors. Fetal neurology. New Delhi: Jaypee Brothers Medical Publishers; 2009. pp. 161-221.

3. Andonotopo W, Stanojevic M, Kurjak A, Azumendi G, Carrera JM. Assessment of fetal behavior and general movements by four-dimensional sonography. Ultrasound Rev Obstet Gynecol 2004;4(2):103-114. 
4. Okado N, Kakimi S, Kojima T. Synaptogenesis in the cervical cord of the human embryo: Sequence of synapse formation in a spinal reflex pathway. J Comp Neurol 1979 Apr;184(3):491-518.

5. Joseph R. Fetal brain and cognitive development. Dev Rev 2000 Mar;20(1):81-98.

6. Pomeroy SL, Volpe JJ. Development of the nervous system. In: Polin RA, Fow WW, editors. Fetal and neonatal physiology. Philadelphia-London-Toronto-Montreal-Sydney-Tokyo: WB Saunders Company; 1992. pp. 1491-1509.

7. Kurjak A, Andonotopo W, Hafner T, Salihagic Kadic A, Stanojevic M, Azumendi G, Ahmed B, Carrera JM, Troyano JM. Normal standards for fetal neurobehavioral developments-longitudinal quantification by fourdimensional sonography. J Perinat Med 2006;34(1):56-65.

8. McCartney G, Hepper P. Development of lateralized behavior in the human fetus from 12 to 27 weeks' gestation. Dev Med Child Neurol 1999 Feb;41(2):83-86.

9. Hepper PG, McCartney GR, Shannon EA. Lateralised behavior in first trimester human foetuses. Neuropsychologia 1998 Jun;36(6):531-534.

10. Kurjak A, Azumendi G, Vecek N, Kupesic S, Solak M, Varga D, Chervenak F. Fetal hand movements and facial expression in normal pregnancy studied by four-dimensional sonography. J Perinat Med 2003;31(6):496-508.

11. Kostovic I, Rakic P. Developmental history of the transient subplate zone in the visual and somatosensory cortex of the macaque monkey and human brain. J Comp Neurol 1990 Jul;297(3):441-470.

12. Kostovic I, Judas M, Petanjek Z, Simic G. Ontogenesis of goaldirected behavior: Anatomo-functional considerations. Int J Psychophysiol 1995 Mar;19(2):85-102.

13. Amiel-Tison C, Gosselin J. From neonatal to fetal neurology: some clues for interpreting fetal findings. In: Pooh RK, KurjakA, editors. Fetal neurology. New Delhi: Jaypee Brothers Medical Publishers; 2009. pp. 374-404.

14. Kostovic I, Rakic P. Development of prestriate visual projections in the monkey and human fetal cerebrum revealed by transient cholinesterase staining. J Neurosci 1984 Jan;4(1): 25-42.

15. Kostovic I, Goldman-Rakic PS. Transient cholinesterase staining in the mediodorsal nucleus of the thalamus and its connections in the developing human and monkey brain. J Comp Neurol 1983 Oct;219(4):431-447.

16. Klimach VJ, Cooke RW. Maturation of the neonatal somatosensory evoked response in preterm infants. Dev Med Child Neurol 1988 Apr;30(2):208-214.

17. Kostovic I, Judas M, Rados M, Hrabac P. Laminar organization of the human fetal cerebrum revealed by histochemical markers and magnetic resonance imaging. Cereb Cortex 2002 May;12(5):536-44.

18. Tau GZ, Peterson BS. Normal development of brain circuits. Neuropsychopharmacology 2010 Jan;35(1):147-168.

19. Visser GHA, Mulder EJH, Prechtl HFR. Studies on developmental neurology on human fetus. Dev Pharmacol Ther 1992;18(3-4):175-183.

20. Mulder EJH, Visser GHA, Bekedan DJ, Prechtl HFR. Emergence of behavioural states in fetuses of type-1 diabetic women. Early Hum Dev 1987 Jul;15(4):231-252.

21. Zoia S, Blason L, D'Ottavio G, Bulgheroni M, Pezzetta E, Scabar A, Castiello U. Evidence of early development of action planning in the human foetus: a kinematic study. Exp Brain Res 2007 Jan;176(2):217-226.
22. Kurjak A, Miskovic B, Stanojevic M, Amiel-Tison C, Ahmed B, Azumendi G, Vasilj O, Andonotopo W, Turudic T, SalihagicKadic A. New scoring system for fetal neurobehavior assessed by three- and four-dimensional sonography. J Perinat Med 2008;36(1):73-81.

23. Kurjak A, Abo-Yaqoub $S$, Stanojevic M, Yigiter AB, Vasilj O, Lebit D, Shaddad AN, Ahmed B, Kavak ZN, Miskovic B, et al. The potential of $4 \mathrm{D}$ sonography in the assessment of fetal neurobehavior-multicentric study in high-risk pregnancies. J Perinat Med 2010;38(1):77-82.

24. Talic A, Kurjak A, Ahmed B, Stanojevic M, Predojevic M, Kadic AS, Di Renzo GC. The potential of 4D sonography in the assessment of fetal behavior in high-risk pregnancies. J Matern Fetal Neonat Med 2011 Jul;24(7):948-954.

25. Talic A, Kurjak A, Stanojevic M, Honemeyer U, Badreldeen A, DiRenzo GC. The assessment of fetal brain function in fetuses with ventrikulomegaly: the role of the KANET test. J Matern Fetal Neonatal Med 2012 Aug;25(8):1267-1272.

26. Kurjak A, Antsaklis P, Stanojevic M, Vladareanu R, Vladareanu S, Neto RM, Barisic LS, Porovic S, Delic T. Multicentric studies of the fetal neurobehavior by KANET test. J Perinat Med 2017 Aug;45(6):717-727.

27. Salihagić Kadić A, Stanojević M, Predojević M, Poljak B , Grubišić-Čabo B, Kurjak A. Assessment of the fetal neuromotor development with the New KANET Test. In: Reissland N, Kisilevsky BS, editors. Fetal development research on brain and behavior, environmental influences, and emerging technologies. Heidelberg, New York, Dordrecht, London: Springer International Publishing Switzerland; 2016. pp. 177-189.

28. Kurjak A, Stanojevic M, Andonotopo W, Salihagic-Kadic A, Carrera JM, Azumendi G. Behavioral pattern continuity from prenatal to postnatal life: A study by four-dimensional (4D) ultrasonography. J Perinat Med 2004;32(4):346-353.

29. Stanojevic M, Kurjak A, Salihagić-Kadić A, VasiljO, Miskovic B, Shaddad AN, Ahmed B, Tomasović S. Neurobehavioral continuity from fetus to neonate. J Perinat Med 2011 Mar;39(2):171-177.

30. Delafield-Butt JT, Trevarthen C. Theories of the development of human communication. In: Cobley P, Schultz PJ, editors. Handbook of communication science, Vol. 1: theories and models of communication. Berlin: De Gruyter Mouton; 2013. pp. 199-221.

31. Graca LM, Cardoso CG, CLode N and Calhaz-Jorge C. Acute effects of maternal cigarette smoking on fetal heart rate and fetal movements felt the mother. J Perinat Med 1991;19(5):385-390.

32. Katz M, Meizner I, Holcberg G, Mazor M, Hagay ZJ, Insler V. Reduction of cessation of fetal movements after administration of steroids for enhancement of lung maturation. Isr J Med Scieince 1988 Jan;24(1):5-9.

33. Prechtl HFR, Einspieler C. Is neurological assessment of the fetus possible? Eur J Obstet Gynecol Reprod Biol 1997 Dec;75(1):81-84.

34. Hepper P. Prenatal development. In: Slater A, Lewis M, editors. Introduction to infant development. New York: Oxford University Press; 2007. pp. 39-101.

35. Trevarthen C, Delafield-Butt JT. Autism as a developmental disorder in intentional movement and affective engagement. Front Integr Neurosci 2013 Jul;7:49-73.

36. Kolb B, Mychasiuk R, Gibb R. Brain development, experience, and behavior. Pediatr Blood Cancer 2014 Oct;61(10): 1720-1723. 
37. Qiu A, Mori S, Miller MI. Diffusion tensor imaging for understanding brain development in early life. Annu Rev Psychol 2015 Jan;66:853-876.

38. Lagercrantz $\mathrm{H}$. The emergence of the mind-a borderline of human viability? Acta Pediatr 2007 Mar;96(3):327-328.

39. Stevens BJ, Johnston CC, Grunau RVE. Issues of assessment of pain and discomfort in neonates. J Obstet Gynecol Neonatal Nurs 1995 Nov-Dec;24(9):849-855.

40. Stevens B, Johnston CC, Petryshen P, Taddio A. The premature infant pain profile. Clin J Pain 1996 Mar;12(1):13-22.

41. Reissland N, Francis B, Mason J. Can healthy fetuses show facial expressions of "pain" or "distress"? PLoS One 2013 Jun; 8(6):e65530.

42. Anand KJS. Clinical importance of pain and stress in preterm neonates. Biol Neonate 1998;73(1):319-324.

43. Salihagić Kadić A, Predojević M. Fetal neurophysiology according to gestational age. Semin Fetal Neonatal Med 2012 Oct;17(5):256-260.

44. Mennella JA, Johnson A, Beauchamp GK. Garlic ingestion by pregnant women alters the odor of amniotic fluid. Chem Senses 1995 Apr;20(2):207-209.

45. Mennella JA, Jagnow CP, Beauchamp GK. Prenatal and postnatal flavor learning by human infants. Pediatrics 2001 Jun;107(6):E88.

46. Lagercrantz $\mathrm{H}$. The emergence of consciousness: science and ethics. Semin Fetal Neonat Med 2014 Oct;19(5):300-305.

47. Ross MG, Nijland JM. Development of ingestive behavior. Am J Physiol 1998 Apr;274(4):R879-R893.

48. El-Haddad MA, Desai M, Gayle D, Ross MG. In utero development of fetal thirst and appetite: potential for programming. J Soc Gynecol Investig 2004 Apr;11(3):123-130.

49. Nicolaidis S, Galaverna O, Meltzer Ch. Extracellular dehydration during pregnancy increases salt appetite of offspring. Am J Physiol (Regulatory Integrative Comp Physol) 1990 Jan;258 (1 Pt):R281-R283.

50. Ross MG, El Haddad M, DeSai M. Unopposed orexic pathways in the developing fetus. Physiol Behav 2003 Jun;79(1):79-88.

51. Eswaran H, Wilson JD, Preissl H, Robinson SE, Vrba J, Murphy P, Rose DF, Lovery CL. Magnetoencepha lographic recordings of visual evoked brain activity in the human fetus. Lancet 2002 Sep;360 (9335):779-780.

52. Hevner RF. Development of connections in the human visual system during fetal mid-gestation: a DiI-tracing study. J Neuropathol Exp Neurol 2000 May;59(5):385-392.

53. Leader LR, Baille P, Martin B, Vermeulen E. The assessment and significance of habituation to a repeated stimulus by the human fetus. Early Hum Dev 1982 Dec;7(3):211-219.

54. Yamaguchi S, Hale LA, D’Esposito M, Knight RT. Rapid prefrontal-hippocampal habituation to novel events. J Neurosci 2004 Jun;24(23):5356-5363.

55. Morokuma S, Fukushima K, Kawai N, Tomonaga M, Satoh S, Nakano H. Fetal habituation correlates with functional brain development. Behav Brain Res 2004 Aug;153(2):459-463.

56. Kawai N, Morokuma S, Tomonaga M, Horimoto N, Tanaka M. Associative learning and memory in a chimpanzee fetus: learning and long-lasting memory before birth. Dev Psychobiol 2004 Mar;44(2):116-122.

57. De Casper AJ, Spence MJ. Prenatal maternal speech influences newborn's perception of speech sound. Inf Behav Dev 1986 Apr-Jun;9(2):33-150.

58. Hepper P, Scott D, Shahidullah S. Newborn and fetal response to maternal voice. J Reprod Infant Psychol 1993;11(3):147-153.
59. Jardri R, Houfflin-Debarge V, Delion P, Pruvo JP, Thomas $\mathrm{P}$, Pins D. Assessing fetal response to maternal speech using a noninvasive functional brain imaging technique. Int J Dev Neurosci 2012 Apr;30(2):159-161.

60. Hepper PG. Foetal "soup" addiction. Lancet 1988;1(8598): 1347-1348

61. Granier-Deferre C, Bassereau S, Ribeiro A, Jacquet AY, Decasper AJ. A melodic contour repeatedly experienced by human near-term fetuses elicits a profound cardiac reaction one month after birth. PLoS One 2011 Feb;6(2):e17304.

62. Delafield-Butt JT, Trevarthen C. Theories of the development of human communication. In: Cobley P, Schultz PJ, editors. Handbook of communication science, Vol. 1: theories and models of communication. Berlin: De Gruyter Mouton; 2013. pp. 199-221.

63. Kurjak A, Azumendi G, Andonopo W, Salihagic-Kadic A. Three- and four-dimensional ultrasonography for the structural and functional evaluation of the fetal face. Am J Obstet Gynecol 2007 Jan;196(1):16-28.

64. Reissland N, Francis B, Mason J, Lincoln K. Do facial expressions develop before birth? PLoS One 2011 Aug;6(8):e24081.

65. Hata T, Kanenishi K, AboEllail MAM, Marumo G, Kurjak A. Fetal consciousness: four-dimensional ultrasound study. DSJUOG 2015;9(4):471-474.

66. Joseph R. Environmental influences on neural plasticity, the limbic system, emotional development and attachment: a review. Child Psychiatry Hum Dev 1999 Spring;29(3):189-208.

67. Humphrey T. The development of the human amygdala during early embryonic life. J Comp Neurol 1968 Jan;132(1):135-165.

68. Salihagic Kadic A, Medic M, Kurjak A. Recent advances in neurophysiology. In: Kurjak A, Azumendi G, editors. The fetus in three dimension. London: Informa Healthcare; 2007. pp. 411-433.

69. Anand KJS. Clinical importance of pain and stress in preterm neonates. Biol Neonate 1998;73(1):319-24.

70. Carmichael SL, Shaw GM, Yang W, Abrams B, Lammer EJ. Maternal stressful life events and risks of birth defects. Epidemiology 2007 May;18(3):356-361.

71. Monk C, Fifer WP, Myers MM, Sloan RP, Trien L, Hurtado A. Maternal stress responses and anxiety during pregnancy: effects on fetal heart rate. Dev Psychobiol 2000 Jan;36(1):67-77.

72. Di PietroJA, HiltonSC,Hawkins M, Costigan KA, Pressman EK. Maternal stress and affect influence fetal neurobehavioral development. Dev Psychol 2002 Sep;38(5):659-668.

73. Golland RS, Jozak S, Warren WB, Conwell IM, Stark RI, Tropper PJ. Elevated levels of umbilical cord plasma corticotropin-releasing hormone in growth-retarded fetuses. J Clin Endocrinol Metab 1993 Nov;77(5):1174-1179.

74. PredojevićM, TalićA,Stanojević M, KurjakA, Salihagić KadićA. Assessment of motoric and hemody-namic parameters in growth restricted fetuses-case study. J Matern Fetal Neonatal Med 2014 Feb;27(3):247-251.

75. Reynolds RM. Glucocorticoid excess and the developmental origins of disease: two decades of testing the hypothesis-2012. Curt Richter Award Winner. Psychoneuroendocrinology 2013 Jan;38(1):1-11.

76. Sandman CA, Wadhwa PD, Chicy-Demet A, Porto M, Garite TJ. Maternal corticotropin-releasing hormone and habituation in human fetus. Dev Psychobiol 1999 Apr;34(3):163-173.

77. Uno H, Lohmiller L, Thieme C, Kemnitz JW, Engle MJ, Roecker EB, Farrell PM. Brain damage induced by prenatal exposure to dexamethasone in fetal rhesus macaques. I. Hippocampus. Brain Res Dev Brain Res 1990 May;53(2):157-167. 
78. Barbazanges A, Piazza PV, Le Moal M, Maccari S. Maternal glucocorticoid secretion mediates long-term effects of prenatal stress. J Neurosci 1996 Jun;16(120):3943-3949.

79. Hayashi A, Nagaoka M, Yamada K, Ichitani Y, Miake Y, Okado N. Maternal stress induces synaptic loss and developmental disabilities of offspring. Int J Dev Neurosci 1998 Jun-Jul;16(3-4):209-216.

80. Rees S, Harding R. Brain development during fetal life: Influences of the intrauterine environment. Neursci Lett 2004 May;361(1-3):111-114.

81. Glover V. Maternal stress or anxiety in pregnancy and emotional development of the child. Br J Psychiatry 1997 Sep;171(2):105-106.

82. Graham YP, Heim C, Goodm SH, Miller AH, Nemeroff CB. The effects of neonatal stress on brain development: implications for psychopathology. Dev Psychopathol 1999 Summer;11(3):545-565.

83. Weinstock $M$. Alterations induced by gestational stress in brain morphology and behaviour of the offspring. Prog Neurobiol 2001 Dec;65(5):427-451.

84. Weinstock M. Does prenatal stress impair coping and regulation of hypothalamic-pituitary-adrenal axis. Neurosci Biobehav Rev 1997 Jan;21(1):1-10.
85. Li J, Olsen J, Vestergaard M, Obel C. Attention-deficit/ hyperactivity disorder in the offspring following prenatal maternal bereavement: a nationwide follow-up study in Denmark. Eur Child Adolesc Psychiatry 2010 Oct;19(10):747-753.

86. Amiel-Tison C, Cabrol D, Denver R, Jarreau PH, Papiernik E, Piazza PV. Fetal adaptation to stress: Part II. Evolutionary aspects; stress-induced hippocampal damage; long-term effects on behavior; consequences on adult health. Early Hum Dev 2004 Jul;78(2):81-94.

87. Cladji C, Dioro J, Meaney MJ. Variations in maternal care in infancy regulate the development of stress reactivity. Biol Psychiatry 2006;34(6):789-798.

88. Francis DD, Dioro J, Plotsky PM, Meaney MJ. Environmental enrichment reverses the effects of maternal separation on stress reactivity. J Neurosci 2002 Sep;22(18):7840-7843.

89. Yang J, Hou C, Ma N, Liu J, Zhang Y, Zhou J, Xu L, Li L. Enriched environment treatment restores impaired hippocampal synaptic plasticity and cognitive deficits induced by prenatal chronic stress. Neurobiol Learn Mem 2007 Feb;87(2):257-263.

90. Bergman K, Sarkar P, Glover V, O'Connor TG. Maternal prenatal cortisol and infant cognitive develop-ment: moderation by infant-mother attachment. Biol Psychiatry 2010 Jun;67(11):1026-1032. 